\title{
Mechanical properties of "flexure wood": compressive stresses in living trees improve the mechanical resilience of wood and its resistance to damage
}

\author{
Benjamin Niez ${ }^{1} \cdot$ Jana Dlouha $^{2} \cdot$ Joseph Gril ${ }^{1,3} \cdot$ Julien Ruelle $^{2} \cdot$ Evelyne Toussaint $^{3} \cdot$ Bruno Moulia $^{1} \cdot$ Eric Badel $^{1}$
}

Received: 26 September 2019 / Accepted: 21 January 2020 / Published online: 10 February 2020

(C) INRAE and Springer-Verlag France SAS, part of Springer Nature 2020

\begin{abstract}
- Key message Mechanical acclimation of young poplars (Populus tremula $\times$ Populus alba, INRA 717-1B4) submitted to periodic stem bending is mainly driven by compressive strains. Flexure wood and compressive flexure wood exhibit higher mechanical resilience and lower mechanical damage.

- Context It is well known that thigmomorphogenesis modulates tree growth and the anatomical structure of wood. However, nothing is known about the mechanical behaviour of the tissues of fresh wood formed under mechanical stimulation.

- Aims We investigated the elastic and plastic properties of the fresh wood of young poplar trees (Populus tremula $\times$ Populus alba, INRA 717-1B4) submitted to periodic controlled stem bending that mimics the mechanical effect of wind.

- Methods For a set of trees, we applied symmetrical bending treatments, which led to the formation of "flexure wood". For another set of trees, asymmetrical bending treatments, including compression (or tension) only, were applied and generated specific wood formation: "compressive flexure wood" and "tensile flexure wood". We investigated the elastic and plastic properties of these woods at the stem and at the local tissue levels.

- Results The results revealed that fresh wood formed under compressive treatments is more resistant to damage (damage reduced by $44 \%)$ and a higher mechanical resilience ( $+33 \%)$, suggesting that this tissue is able to withstand higher mechanical strains than "normal wood". This improvement could explain the higher mechanical strength of the stem to bending $(+42 \%)$.

- Conclusion When trees experience repetitive mechanical stimulations, they adjust the plastic plastic behaviour of their wood in a way that improves the mechanical safety. This demonstrates the adaptive benefit of the mechanical acclimation of trees.
\end{abstract}

Keywords Mechanical stress $\cdot$ Thigmomorphogenesis $\cdot$ Fresh wood $\cdot$ Mechanical behaviour

Handling Editor: Jean-Michel Leban

Contributions of the co-authors EB, JD and BM conceived the study. $\mathrm{BN}$ performed the experiments, data collection and laboratory work. JR performed the MFA measurements. BN initially summarized and analysed the data and wrote the initial draft. BN, JD, JG, JR, ET, BM and EB contributed to the writing of the final draft.

Eric Badel

eric.badel@inrae.fr

Benjamin Niez

benjamin.niez@live.fr

Jana Dlouha

jana.dlouha@inrae.fr

Joseph Gril

joseph.gril@cnrs.fr

Julien Ruelle

julien.ruelle@inrae.fr
Evelyne Toussaint

evelyne.toussaint@uca.fr

Bruno Moulia

bruno.moulia@inrae.fr

Université Clermont-Auvergne, INRAE, PIAF, 63000 Clermont-Ferrand, France

2 Université de Lorraine, AgroParisTech, INRAE, Silva, 54000 Nancy, France

3 Université Clermont-Auvergne, CNRS, Institut Pascal, 63000 Clermont-Ferrand, France 


\section{Introduction}

Trees are slender living structures that grow under fluctuating environmental conditions (water and light resources, snow, wind, etc.). In response to environmental signals, trees continuously modulate their growth and material properties. This process is called tree acclimation, i.e. trees implement suitable physiological functioning to withstand variable conditions. The existence of this acclimation process is well known (Jaffe 1973; Telewski 1989), but the underlying mechanisms of this acclimation remain poorly understood. In the context of global climate change, predictions forecast an increase in storm frequency and intensity and a decrease in the intensity of normal winds that allow the daily mechanical acclimation of trees (Haarsma et al. 2013; Hawcroft et al. 2018). It is therefore essential to better understand the process of the mechanical acclimation of trees.

Trees that grow in windy environments mainly experience bending stresses. It is well known that trees perceive mechanical strains (Coutand and Moulia 2000; Moulia et al. 2015) and adjust their development accordingly (Biddington 1986; Jaffe et al. 1984; Kern et al. 2005; Niez et al. 2018; Telewski 1995; Telewski and Pruyn 1998): when tree stems and branches experience bending stress in windy environments, primary growth is reduced, whereas secondary growth is highly enhanced, especially in the direction of stem bending. These mechanosensitive growth responses to short-term bending produced by wind are known as thigmomorphogenesis (Jaffe 1973).

The growth modulations of trees submitted to bending oscillations (symmetrical bending) are the result of modifications of the anatomical, hydraulic and mechanical properties of the wood that are involved in sap conduction and mechanical support of the tree (Badel et al. 2015). Telewski (1989) coined the expression "flexure wood (FW)", to designate the wood formed under symmetrical bending and having a different structure than "normal wood (NW)" (Telewski 1989). In hardwoods, it is denser and has smaller and fewer vessels (Kern et al. 2005; Neel and Harris 1971). In terms of mechanical properties, few studies on Abies fraseri and hybrid poplars indicated a lower longitudinal elastic modulus (E) in flexure wood (Kern et al. 2005; Pruyn et al. 2000; Telewski 2016; Telewski and Pruyn 1998). According to Kern et al. (2005), flexure wood seems to have a lower rupture strength (MOR) than NW.

In the abovementioned studies, the intensity of stem bending was not controlled and the authors could not distinguish the effect of tensile stresses from compressive stresses, both being systematically involved during a bending event. Roignant et al. (2018) first investigated the difference between tensile and compressive stimulations by applying controlled unidirectional bending. Based on their results on anatomical structure, Roignant et al. (2018) suggested updating the generic term of "flexure wood" to distinguish the wood formed under tensile stresses from wood formed under compressive stresses: these two types of wood were called "tensile flexure wood (TFW)" and "compressive flexure wood (CFW)", respectively (Roignant et al. 2018). For hybrid poplars (P. tremula $\times$ P. alba, clone INRA 717-1B4), they showed that tensile flexure wood and compressive flexure wood have less vessels and thicker fibres than normal wood. Tensile stress has additional repercussions on wood anatomy: vessels are smaller (both in length and diameter) and fibres are smaller as well. Moreover, fibres of tensile flexure wood show a higher proportion of G-layer (Roignant et al. 2018) with a smaller microfibril angle (MFA), even if this angle remains much higher than in tension wood developed by trees in response to gravitropic load (Jourez 1997; Roignant et al. 2018; Ruelle 2014).

Because of the strong relationship between anatomical features and mechanical properties (Barnett and Bonham 2004; Clair and Thibaut 2014; Evans and Ilic 2001; Fournier et al. 2006; Xu and Liu 2004; Yang and Evans 2003), all these modifications of wood anatomy suggest that wood mechanical properties may be modulated by the thigmomorphogenetic process. In our study, we hypothesised that acclimation to stem bending could be a combination of acclimation to tension and compressive stresses. Thus, we investigated the effect of both symmetric and asymmetric bending to compare a controlled mechanical stimulation to one close to natural oscillations under the wind. We observed not only wood structure and elastic properties but damage and rupture properties as well since they may play a decisive role in the ability of the plant to survive strong wind events. Wood mechanical properties were measured both on stem segments and at tissue level.

\section{Materials and methods}

\subsection{Plant material}

Trees were grown following Niez et al. (2018). Hybrid poplars $(P$. tremula $\times P$. alba, clone INRA 717-1B4) were clonally multiplied in vitro on $1 / 2$ strength Murashige and Skoog medium (Mader et al. 2016; Murashige and Skoog 1962; Roignant et al. 2018). After 2 months of potting and acclimation, we selected 30 young trees for their homogeneity and transferred them to a greenhouse at $22 \pm 1{ }^{\circ} \mathrm{C}$ (day) and $19 \pm 1{ }^{\circ} \mathrm{C}$ (night) under natural light (Clermont-Ferrand, France, $45.77^{\circ} \mathrm{N}$, $3.14^{\circ} \mathrm{E}$ ). They were planted in $10-\mathrm{L}$ pots that were filled with a substrate composed of one-third black peat and two-thirds local clay-humic Limagne soil (Bornand et al. 1975; Roignant et al. 2018). As a complement to watering, trees received $200 \mathrm{~g}$ of nutritional solution per week. Trees were divided into three equal groups submitted to different mechanical treatments: trees that experienced asymmetrical stem bending (MSa), trees that experienced symmetrical stem bending (MSs) and control trees that were grown without mechanical 
stimulations (C). These three treatments were applied for 5 months, from May to September 2017.

\subsection{Application of periodic mechanical stresses: asymmetrical and symmetrical bending}

The mechanical stimulations began 8 weeks after the trees were repotted in 10-L pots and reached an average height of $50 \mathrm{~cm}$. The bending stimulations were applied to the $40-\mathrm{cm}$ basal part of the stem (referred to as the "bent segment"). Two types of bending treatment were applied: asymmetric (Fig. 1a) and symmetric (Fig. 1b), i.e. either one half of the stem was submitted only to compression (resp. tension) for MSa trees, or wood was alternatively submitted to tension and compression for MSs trees. Bending treatments consisted of a session of three stem bendings in each direction and were repeated three times a day (9 a.m., 12 p.m. and 3 p.m.), 5 days per week. We controlled the intensity of the maximum strain on the stem periphery using constant-curvature templates (Coutand et al. 2009; Niez et al. 2018). This method made it possible to apply an identical strain field along $40 \mathrm{~cm}$ of the "bent segment". We adjusted the radius of curvature of the template every week in order to maintain a maximal peripheral longitudinal strain of the bark as close as possible to $1 \%$ during the 5 months of treatment (Fig. 1c). This intensity of strain was a critical limit value: high enough to significantly modulate tree growth (Niez et al. 2018; Roignant et al. 2018) and low enough to avoid mechanical damage of the stem.

The maximal longitudinal strain $\varepsilon_{\max }$ applied to the periphery of the stem was computed as follows (Coutand et al. 2009; Moulia et al. 2015):

Fig. 1 Bending treatments. a Asymmetrical bending treatments. b Symmetrical bending treatments. $\mathbf{c}$ Principle of stem bending: the stem is bent on a plastic constant-curvature template that imposes a pure bending. $\mathrm{D}_{/ /}$is the diameter of the stem in the direction of the bending treatment, $\rho$ is the radius of curvature of the template, $\mathrm{L}_{0}$ is the initial length of the "bent segment", namely $40 \mathrm{~cm}$, and $\varepsilon_{\max }$ is the maximal strain applied to the stem bark $\varepsilon_{\max }=\frac{D_{/ /}}{D_{/ /}+2 \times \rho}$

where $\rho$ is the radius of curvature of the template and $\mathrm{D}_{/ /}$is the diameter of the stem in the direction of the bending. The presentation time was short enough $(<2 \mathrm{~s}$ per bending) to avoid a gravitropic response that occurs after only $30 \mathrm{~s}$ of tree tilting (Bonnesoeur et al. 2016; Jourez and Avella-Shaw 2003; Perbal and Drissecole 1993; Roignant et al. 2018).

\subsection{Sampling and preparation of wood specimens}

The 40-cm-long bent segments and corresponding 40-cmlong basal segment were collected in trees submitted to bending and in control trees, respectively (Fig. 2a). A centred stem segment of $34 \mathrm{~cm}$ in length from half of the trees $(n=5)$ for each treatment was used for stem mechanical characterisation. For the other half, we sampled millimetric beams in three areas of interest: in the wood formed under tension and/or compression and in the neutral area, i.e. wood that theoretically experienced the lowest level of strain during the bending treatment (Fig. 2b). Because only few millimetres of wood were formed during the bending treatment, we made beams with a $2 \times 2 \mathrm{~mm}^{2}$ cross-section. We developed a specific protocol using a plane and a reamer in order to obtain very precise dimensions of the parallelepiped beams (Fig. 2c). During all steps of the specimen preparation, beams were moistened to avoid drying. The beams used for three-point micro-bending and for Charpy impact tests were sampled at the centre of the bent part of the stem, in the 15-20 cm segment and 20-27 cm segment, respectively (Fig. 2a).

Following Roignant et al. (2018), the wood formed under compressive stresses (resp. tensile stresses) is referred to as

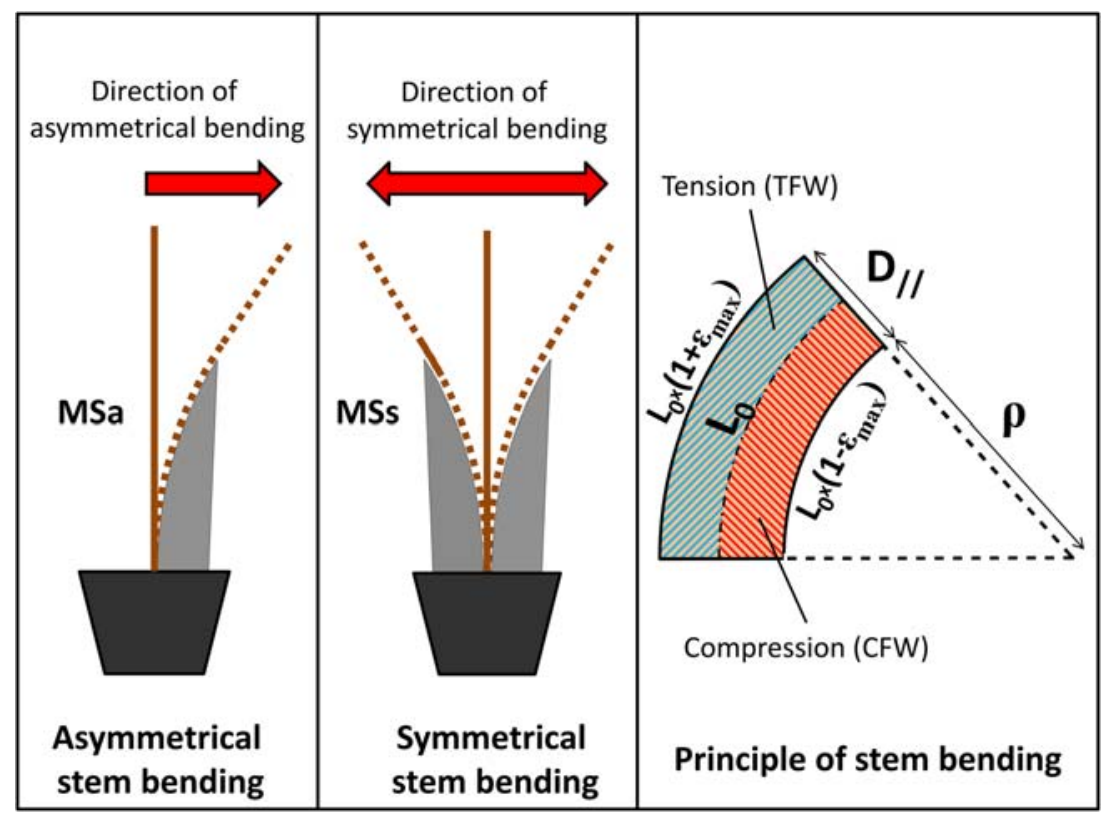


Fig. 2 Sampling protocols for mechanical characterisations. a Half of the stems were used for the macroscopic three-point bending test (red segment). The other stems were used for microscopic characterisation at the tissue level: 70-mm-long segments were used for Charpy impact tests (yellow segment), while 50-mmlong segments were used for micro-bending tests (blue segment). b Localisation of millimetric beams in the three areas of interest of the transversal cross-section. TFW (resp. CFW) stands for wood formed under tensile (resp. compressive) treatments. N stands for wood formed in the neutral area of the stem, i.e. where strains were theoretically the lowest. c Milling of the $2 \times 2$ $\mathrm{mm}^{2}$ (cross section) millimetric beams using a sample holder specially designed for this purpose

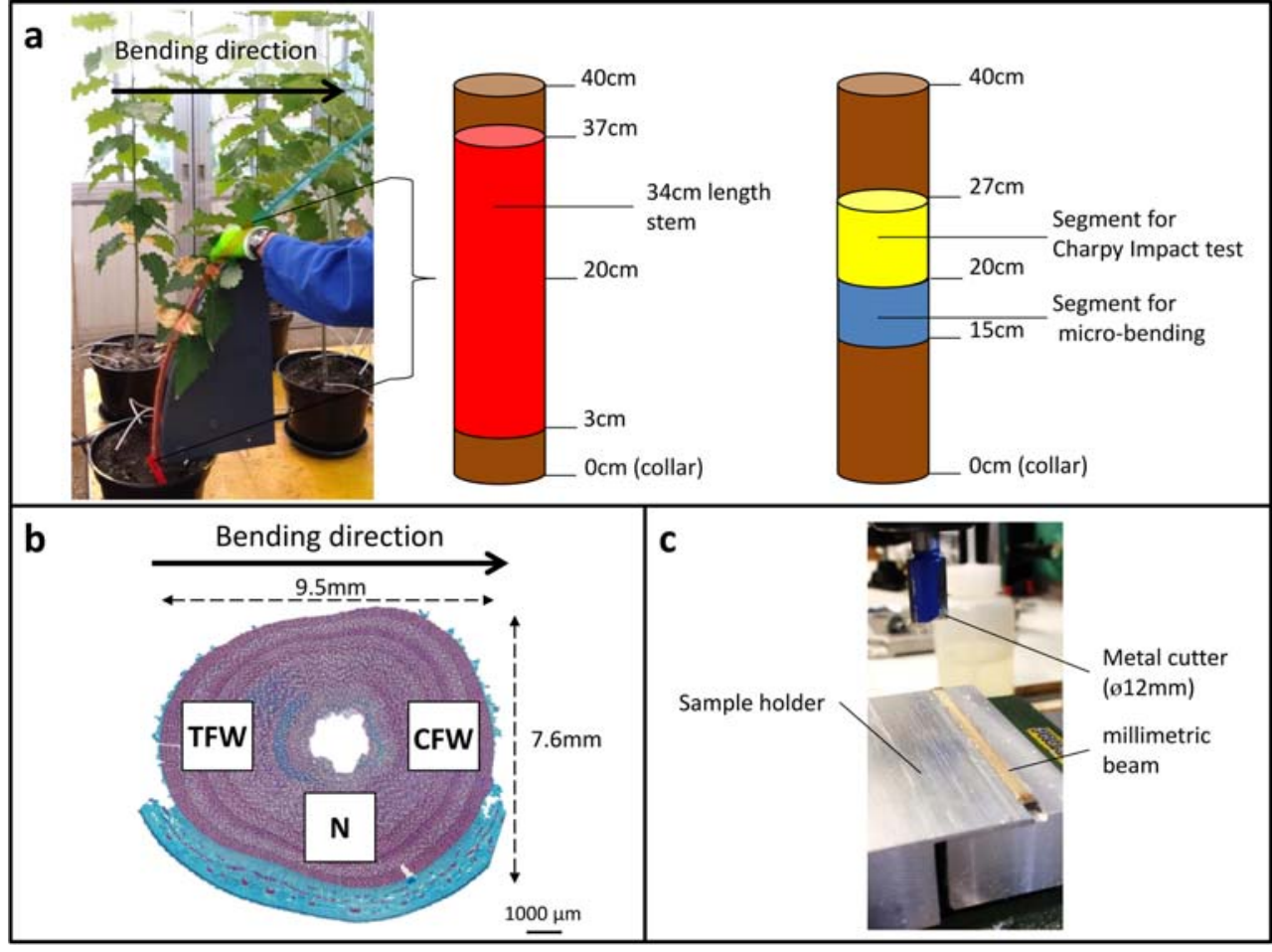

CFW (resp. TFW), and for MSs trees, the "flexure wood" is referred to as FW. The wood formed in the neutral area is defined as MSa-N and MSs-N for MSa and MSs trees, respectively, and collectively labelled NeW. For the sake of simplicity, the wood formed in control trees (C) is referred to as "normal wood (NW)" (Glossary of abbreviations).

\subsection{Basic density and microfibril angle measurements}

Basic density was measured on millimetric beams after mechanical characterisation. Basic density is defined as the ratio between dry mass and saturated volume. Saturated volume was measured using the method of hydrostatic weighting based on Archimedes' principle. Dry mass was measured after drying the beams for $48 \mathrm{~h}$ at $104{ }^{\circ} \mathrm{C}$.

The same specimens were then used to measure the microfibril angle (MFA) of the different wood types. The measurements of average MFA using an X-ray diffractometer (Supernova, Oxford-Diffraction, Abingdon-on-Thames, UK) were performed at the SILVATECH platform (INRA, Nancy, France). This device has a kappa geometry and contains a CCD detector, an X-ray tube, and a sample holder. MFA values were estimated using the following equation (Verrill et al. 2006):

$M F A=0.8 \times 0.6 \times\left(\sigma_{1}+\sigma_{2}\right)$

where $\sigma_{1}$ and $\sigma_{2}$ are the widths of the Gaussian fits of the diffraction curves.

\subsection{Elastic and plastic behaviour of fresh wood at tissue level}

Millimetric beams were first tested using the Deben microtest three-point micro-bending system equipped with a $50 \mathrm{~N}$ load cell. A camera positioned in front of the mechanical bench monitored the displacement of the central part of the beam. This video monitoring made it possible to consider the artefact caused by a possible transversal punching in the fresh wood. After three preliminary loading cycles in the linear elastic range, samples were submitted to a fourth loading cycle in the plastic domain (maximal strain $=0.8 \%$ ), and then finally loaded until rupture. The resulting force-displacement curve was analysed using a dedicated Matlab code. The maximal longitudinal stress $\sigma$ and strain $\varepsilon$ (Fig. 3) in the cross section were calculated according to beam theory, assuming a linear stress-strain relationship within the central cross-section (Timoshenko 1930a; Timoshenko 1930b):

$\sigma=\frac{P \times L \times h}{8 \times I_{z}}$

$\varepsilon=\frac{6 \times h \times \delta}{L^{2}}$

where $P$ is the force applied by the bench device to the sample, $L$ is the span, $\delta$ is the displacement of mobile crossties, $h$ is the thickness of the millimetric beam, and $I_{z}=\mathrm{h}^{4} / 12$ is the second moment of cross-sectional area of the beam. 


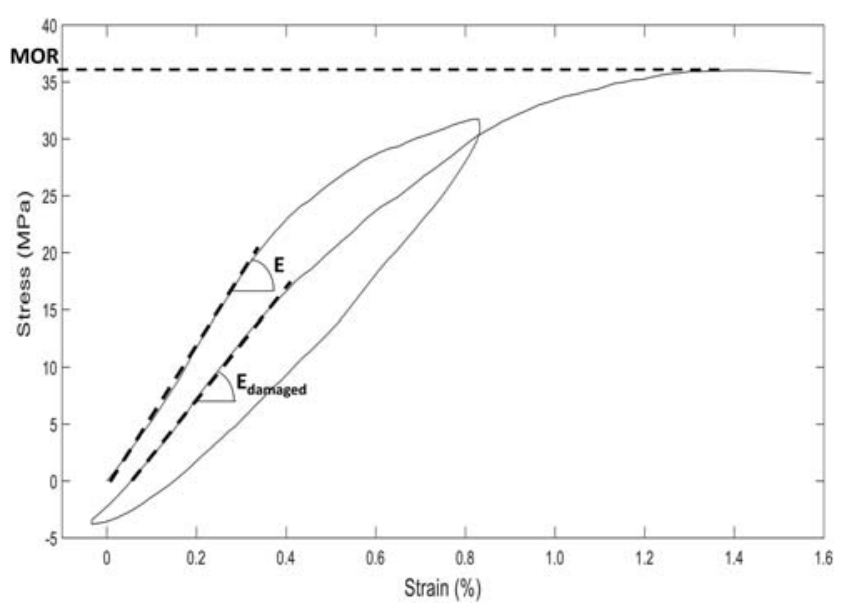

Fig. 3 Typical experimental stress-strain curve from micro-bending tests. Three preliminary elastic cycles (not represented here) were performed in order to measure the elastic Young modulus $(E)$. The strain was then increased until $0.8 \%$ in order to generate tissue damage. One final cycle was performed to characterise the damage. $E_{\text {damaged }}$ stands for the longitudinal elastic modulus after damage $(0.8 \%$ strain). Damage was characterised by the relative decrease of the elastic modulus according to Eq. 7. MOR stands for the fresh wood modulus of rupture

From this curve, we extracted several mechanical parameters. First, we computed the modulus of elasticity $(E)$ :

$E=\frac{\sigma}{\varepsilon}=\frac{P \times L^{3}}{48 \times \delta \times I_{z}}$

from the slope of the force-displacement curve within the strain interval of $[0 \% ; 0.5 \%]$, assumingly included in the linear elastic range. Then, a damage parameter $D_{a}$ expressing the loss of rigidity of wood following a strain of high intensity (plastic field) was defined as the relative difference between the initial modulus of elasticity $(E)$ and the damaged modulus of elasticity $\left(E_{\text {damaged }}\right)$ as follows:

$D_{a}=\frac{E-E_{\text {damaged }}}{E} \times 100$

$E_{\text {damaged }}$ represents the slope of the linear part of the last loading step.

Finally, the specific modulus $\left(E_{s}\right)$ was computed as the ratio between the elastic modulus (E) and the basic density. For a cellular material such as wood, this specific modulus reflects the rigidity of the cell wall (Ashby 1983).

\subsection{Dynamic fracture of fresh wood at the tissue level}

Dynamic fracture of the millimetric beams was performed with a Charpy impact test device that we developed in our lab (Fig. 4a). It is dedicated to the small dimensions and properties of our fresh wood beams (Fig. 4b). The pendulum $(m)$ is dropped with no initial speed (ensured by an electromagnet for reproducibility) from an initial angular position $\alpha_{\text {initial }}\left(-90^{\circ}\right)$. It sways and breaks the beam (at position $0^{\circ}$ ) and then rises up to the final position $\alpha_{\text {final }}\left(<90^{\circ}\right)$. The difference between the two positions of interest $\left(\alpha_{\text {initial }} ; \alpha_{\text {final }}\right)$ corresponds to the difference in potential energy that matches the total energy dissipated during the test $\Delta \mathrm{E}$ (Fig. 10 in the Appendix section). This loss of energy $\Delta \mathrm{E}$ is composed of the fracture energy of the beam $\mathrm{E}_{\text {fracture }}$ and the energy dissipated by
Fig. 4 Charpy impact test especially developed for breaking energy measurements. a Principle of the Charpy impact test: starting from the horizontal position, the pendulum sways, breaks the wood beam and continues its movement. The difference in height between the initial and final positions indicates the total loss of energy $\Delta \mathrm{E}$ that is dissipated (fracture energy of the sample + friction). $m$ is the mass at the extremity of the pendulum, $L$ is the length of the pendulum and $g$ is the gravitational acceleration. The positions of the pendulum are continuously recorded by an angle position sensor that makes it possible to determine the corresponding heights $\left(\mathrm{h}_{\text {initial }}, \mathrm{h}_{\text {final }}, \Delta \mathrm{h}\right)$. b Large view and details of the device

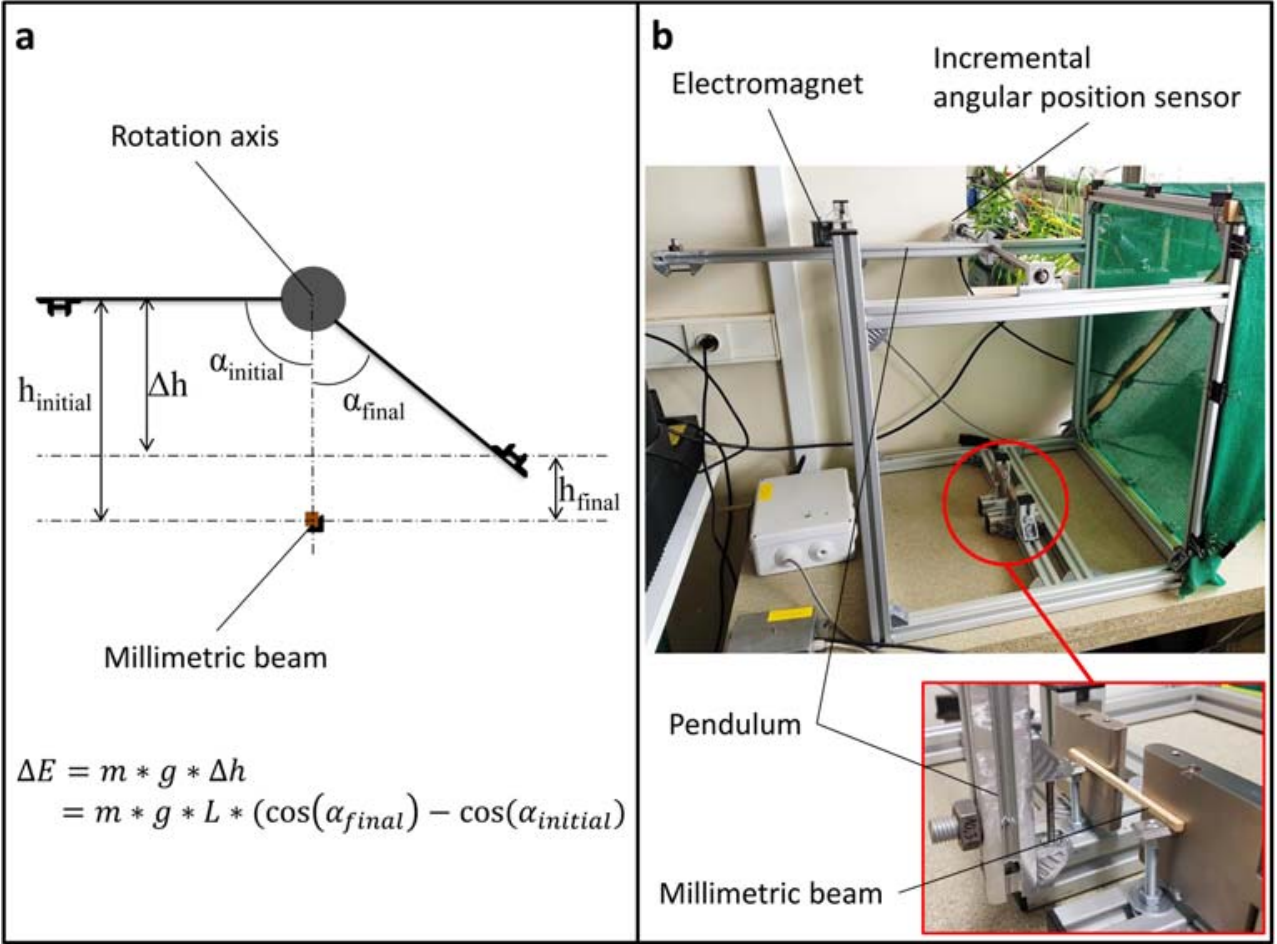


friction of the device itself $\mathrm{E}_{\text {friction }}$, a fixed value we previously measured:

$$
\begin{aligned}
\Delta E & =m \times g \times L \times\left(\cos \alpha_{\text {final }}-\cos \alpha_{\text {initial }}\right) \\
& =E_{\text {fracture }}+E_{\text {friction }}
\end{aligned}
$$

where $L$ is the length of the pendulum (cm), $g$ the gravitational acceleration $\left(\mathrm{m} \mathrm{s}^{-2}\right.$ ), and $m=173.92 \mathrm{~g}$ is the mass of the pendulum. The fracture energy was then normalised by the beam cross-sectional area in order to obtain the resilience of the wood.

We tested three beams from $\mathrm{C}$ trees, four CFW beams, four TFW beams, three MSa-N beams, seven FW beams and three MSs-N beams (Table 3 in the Appendix section).

\subsection{Elastic and rupture properties at the stem level}

Thirty-four-centimetre-long stem segments were tested in an Instron 5565 three-point bending system equipped with a 1$\mathrm{kN}$ load cell. For the same reason as for micro-bending, the displacement of the stem was monitored by a camera fixed in front of the mechanical bench. The analysis of the resulting curves was similar to that of the micro-bending one curves (Eq. 4 and Eq. 5), except that parameter " $h$ " now stands for the diameter of the stem at mid-span and the second moment of cross-sectional area $I_{z}$ was accurately measured by image segmentation of the cross-section of the stem at mid-span (Niez et al. 2018). On the basis of the stress-strain curve, we computed the elastic modulus $(E)$ and the modulus of rupture of the stem (MOR), i.e. the maximal bending stress experienced by the stem before mechanical rupture.

We tested five samples for each growth condition (Table 3 in the Appendix section). For MSa and MSs trees, the mechanical tests were performed in the direction of the bending treatments.

\subsection{Statistical analyses}

All measured and computed data were statistically analysed using Microsoft Excel 2010 software. Student's $t$ tests were used to compare results in terms of specific modulus, damage,

Table 1 Modulation of basic density and on microfibril angle (MFA) of woods formed under different mechanical stimulations. NW represents the "normal wood" (no-bending stimulation), CFW (resp. TFW) refers to wood tissues that experienced compressive (resp. tensile) strain only during the stem bending treatment. MSa-N and MSs-N refer to wood tissues resilience, $u$ and MOR $(p<0.05)$. The values presented in this article correspond to median values.

\section{Results}

\subsection{Microfibril angle and basic density}

Mechanical stimulations of the tree stem implied modifications of wood material structure (Table 1). compressive flexure wood and flexure wood exhibited a higher microfibril angle compared to normal wood of control trees $(24.9 \pm$ $\left.3.2^{\circ}\right)$ : we observed an increase of $+9.2 \%\left(27.2 \pm 2.3^{\circ}, p=\right.$ $\left.4.10^{-7}\right)$ and of $+17.2 \%\left(29.2 \pm 2^{\circ}, p=2.10^{-13}\right)$, respectively. At the intra-tree scale, we noticed that the microfibril angle was also higher in compressive flexure wood $(+13 \%$; $p=$ $\left.1.10^{-7}\right)$ and flexure wood $\left(+19.6 \% ; \mathrm{p}=2.10^{-16}\right)$ than in neutral wood (either MSa-N or MSs-N). No significant difference was observed between tensile flexure wood and normal wood or neutral wood $\left(\mathrm{MFA}=25.6^{\circ}\right)$.

Similar trends were observed for basic density. We observed an increase of $+16.8 \%$ and $+18.4 \%$, respectively, for compressive flexure wood and flexure wood compared to normal wood. Moreover, at the intra-tree scale, compressive flexure wood and flexure wood showed a higher basic density than corresponding neutral wood $(+15.8 \%$ and $+6 \%$, respectively). No modification was observed on tensile flexure wood basic density compared to normal wood and neutral wood.

\subsection{Specific elastic modulus of fresh wood tissues}

The mechanical properties of wood were also modulated by the mechanical stimulations of the tree stem (Fig. 5). We observed different cases. Once again, compressive flexure wood showed a lower specific modulus $(11.8 \pm 1.2 \mathrm{GPa}),-23 \%$ $(p=0.0015)$, than normal wood $(15.3 \pm 1.1 \mathrm{GPa})$, as did flexure wood $(11.5 \pm 0.2 \mathrm{GPa})$ compared to normal wood ($24.9 \% ; p=0.00004)$. On the other hand, tensile stresses alone did not significantly affect the specific modulus. Neutral wood showed a higher specific modulus than normal wood: we observed an increase of $+13.2 \%(p=0.004)$ for MSa-N and + $7.6 \%(p=0.048)$ for MSs-N. However, at the intra-tree scale,

in the neutral line during the asymmetrical (resp. symmetrical) stem bending treatment. FW (flexure wood) refers to wood tissues that alternatively experienced tension and compression strain (symmetrical bending treatment). Values presented are median values, and letters show the signifi-

\begin{tabular}{|c|c|c|c|c|c|c|}
\hline & NW & CFW & TFW & MSa-N & FW & MSs-N \\
\hline Basic density & $0.40 \pm 0.01 \mathrm{a}$ & $0.47 \pm 0.02 b c$ & $0.41 \pm 0.01 \mathrm{a}$ & $0.41 \pm 0.01 \mathrm{a}$ & $0.48 \pm 0.02 b$ & $0.45 \pm 0.01 \mathrm{c}$ \\
\hline MFA $\left(^{\circ}\right)$ & $24.9 \pm 3.2 \mathrm{a}$ & $27.2 \pm 2.3 b$ & $25.6 \pm 4.1 \mathrm{a}$ & $24.1 \pm 2.2 \mathrm{a}$ & $29.2 \pm 2 c$ & $24.4 \pm 0.9 \mathrm{a}$ \\
\hline
\end{tabular}
cant differences between these values (Student $t$ test, $p<0.05$ ) 


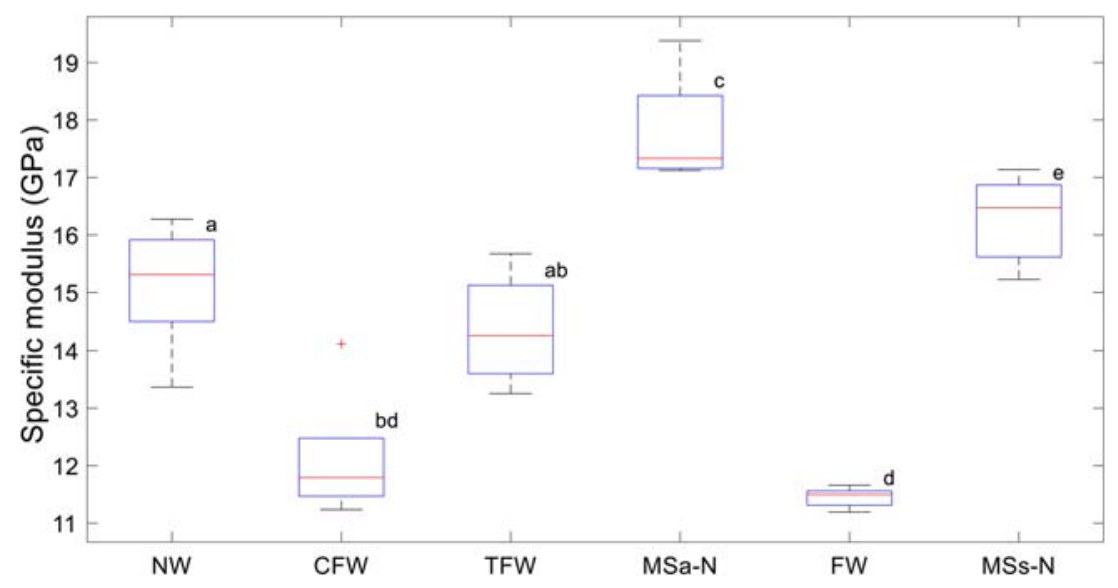

Fig. 5 Modulations of the specific modulus of wood formed under different mechanical treatments. NW represents the "normal wood" (nobending stimulation), TFW (resp. CFW) refers to the wood tissue formed under tensile (resp. compressive) stresses. FW stands for the "flexure wood" formed under symmetrical stem bending (tissues alternatively experienced compression and tensile strain). MSa-N and MSs-N are

wood tissues formed in the neutral area. The lines in the boxplot represent the median values. The bottom and top edges of the box indicate the 25 th and 75th percentiles, respectively. The "+" symbol stands for outliers. Different letters show the significant differences between these values (Student $t$ test, $p<0.05$ )

we observed that both compressive flexure wood and flexure wood had a much lower specific modulus than the corresponding neutral wood. This sharp decrease reached $-32 \%$ ( $p=0.005)$ for asymmetric stimulations (between MSa-N and compressive flexure wood) and $-30.2 \%(p=0.0001)$ for symmetrical stimulations (between MSs-N and flexure wood).

\subsection{Fresh tissue damage}

Compressive flexure wood and flexure wood specimens submitted to a plastic strain of $0.8 \%$ exhibited highly reduced damage compared to other wood tissues (NW, NeW and TFW). Indeed, at the inter-tree scale, compressive flexure wood damage was $-44.1 \%$ lower than in normal wood $(p=$ 0.002 ) and flexure wood damage was also $-36.9 \%$ ( $p=$ 0.0006) lower than in normal wood. At the intra-tree scale, compressive flexure wood and flexure wood were also less damaged than the corresponding neutral wood, $-49 \%(p=$ $0.005)$ and $-16.1 \%(p=0.04)$ lower, respectively. Once again, tensile stresses did not impact the wood damage behaviour (Fig. 6).

\subsection{Mechanical resilience of fresh wood tissues}

The resilience of compressive flexure wood $\left(62.9 \pm 4.7 \mathrm{~kJ} / \mathrm{m}^{2}\right)$ was much higher than the resilience of $\mathrm{MSa}-\mathrm{N}(+30.4 \%, p=$

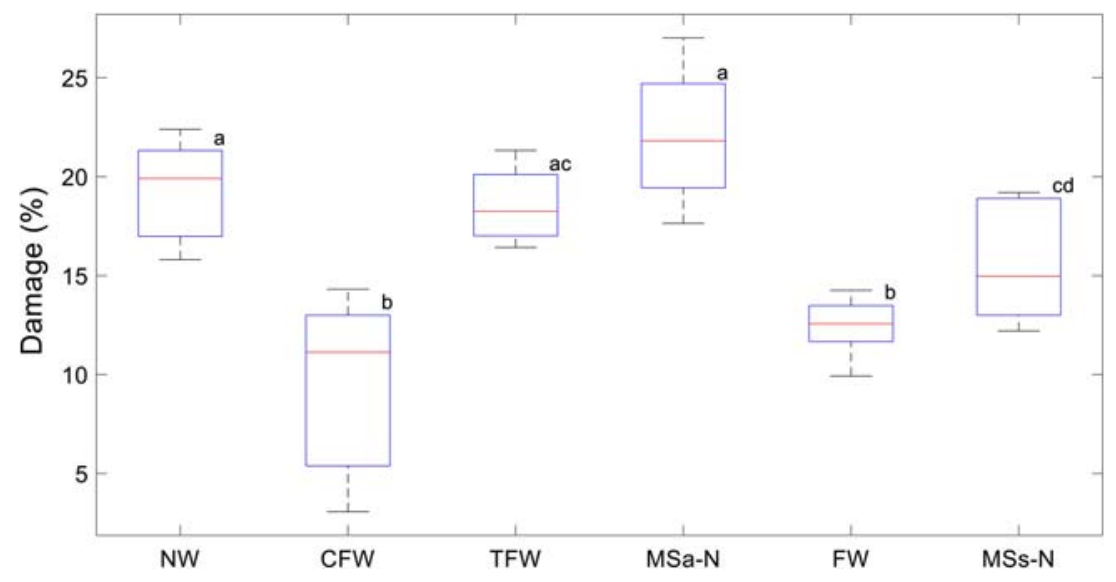

Fig. 6 Modulations of damage after a high intensity strain $\left(\varepsilon_{\max }>0.8 \%\right)$ for wood formed under different mechanical treatments. NW represents "normal wood" (no-bending stimulation), TFW (resp. CFW) is the wood tissue formed under tensile (resp. compressive) stresses, FW stands for the "flexure wood" (tissues alternatively experienced compression and

tensile strain). MSa-N and MSs-N are wood tissues formed in the neutral area where longitudinal strains are the lowest. The lines in the boxplot represent the median values. The bottom and top edges of the box indicate the 25th and 75th percentiles, respectively. Different letters show the significant differences between these values (Student $t$ test, $p<0.05$ ) 
$0.04)$ and of normal wood $(+33.2 \%, p=0.006)$ (Fig. 7). This huge increase was observed for flexure wood whose resilience was $60.2 \pm 12.6 \mathrm{~kJ} / \mathrm{m}^{2}(+27 \%)$. However, this result cannot be statistically verified because of the great variability of the data $(p=0.07>0.05)$. The resiliences of the other wood tissues were all similar: tensile stresses did not affect wood tissue resilience.

\subsection{Stem mechanical strength}

The rupture event was local in the stem and always occurred in the area where wood was under compressive stresses. The results showed that asymmetrical and symmetrical bending treatments highly increased the stem modulus of rupture (MOR), i.e. stem mechanical strength to bending (Table 2). This parameter increased from $35 \pm 1.4 \mathrm{MPa}$ for control trees to $49.8 \pm 6.2 \mathrm{MPa}$ and $45.5 \pm 10.1 \mathrm{MPa}$, respectively, for $\mathrm{MSa}$ and $\mathrm{MSs}$ trees, corresponding to an increase of $+42.1 \%$ ( $p=$ $0.003)$ and $+30 \%(p=0.04)$.

\section{Discussion}

\subsection{Bending of tree stems makes the wood density and microfibril angle higher}

Several previous studies on different species, including gymnosperms and angiosperms (poplar hybrids, loblolly pine and Fraser fir), have shown that "flexure wood" presents a higher basic density and a lower elastic modulus than non-stimulated trees (Kern et al. 2005; Pruyn et al. 2000; Telewski and Jaffe 1986a, b). These results lead to a lower specific modulus of flexure wood. Our investigations are consistent with these previous observations since flexure wood showed a lower specific modulus compared to normal wood. For MSa trees, only compressive treatments significantly decreased the specific modulus. This decrease was mainly due to the increase of compressive flexure wood basic density, which has a lower vessel density ( $-19 \%$ compared to "normal wood") and a thicker cell wall in terms of fibres (+ $10 \%$ compared to "normal wood"), as demonstrated in Roignant et al. (2018).

Information about microfibril angle variation in flexure wood is sparse and variable. However, studies on dry wood specimens showed that the cell wall elastic modulus is highly correlated with microfibril angle (Evans and Ilic 2001; $\mathrm{Xu}$ and Liu 2004; Yang and Evans 2003). Thus, it is interesting to note that for fresh wood, observed variations in the specific modulus (ratio of elastic modulus and basic density) also show high correlations with microfibril angle variations (Fig. 8). Our results indicate that most of the variations in cell wall rigidity in wood produced after tree bending are the result of ultrastructural changes at the cell wall level and that flexure wood, formed under alternative compressive and tensile stresses, is mainly driven by compressive stimulations that lead to similar anatomy and a specific elastic modulus. Higher density and higher microfibril angle may enhance stem flexibility as well as its strength. However, studies of flexure wood sometimes report a slight decrease in MOR (Kern et al. 2005). It is therefore interesting to take a deeper look into the post-elastic linear behaviour of wood tissues formed after symmetrical and asymmetrical bending.

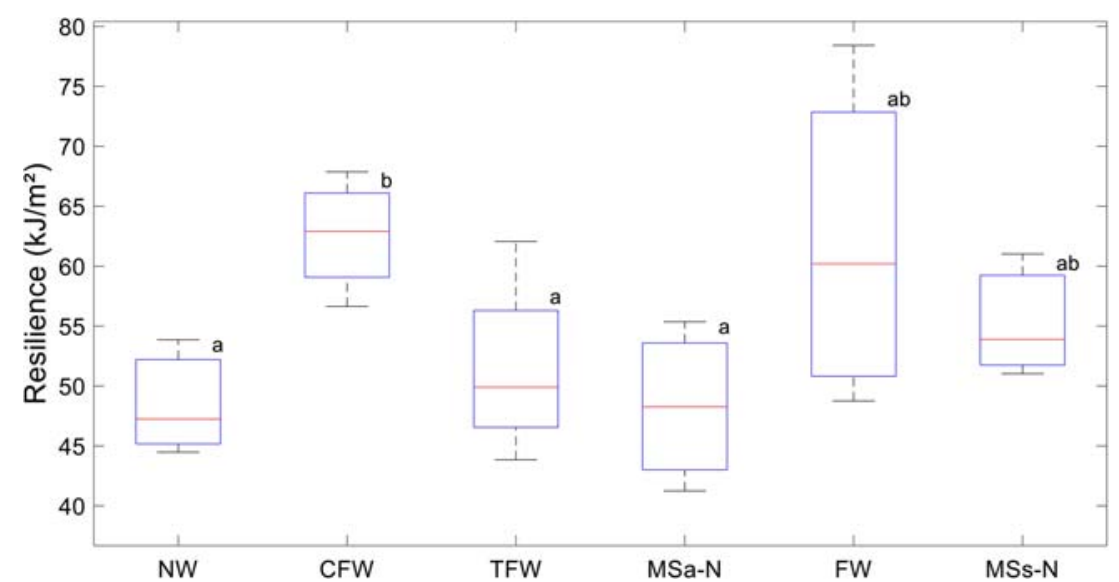

Fig. 7 Modulations of the wood resilience of woods formed under different mechanical treatments. NW represents "normal wood" (nobending stimulation), TFW (resp. CFW) is wood tissue formed under tensile (resp. compressive) stresses, FW stands for the "flexure wood" (tissues alternatively experience compression and tensile strain). MSa-N

and MSs-N are wood tissues formed in the neutral area where longitudinal strains are the lowest. The lines in the boxplot represent the median values. The bottom and top edges of the box indicate the 25 th and 75 th percentiles, respectively. Different letters show the significant differences between these values (Student $t$ test, $p<0.05$ ) 
Table 2 Modulation of modulus of rupture (MOR) of stem that experiences different mechanical stimulations. MSa and MSs refer to stems that experienced asymmetrical and symmetrical bending treatments, respectively. C refers to control trees. Values presented are median values, and letters show the significant differences between these values (Student $t$ test, $p<0.05)$

\begin{tabular}{llll}
\hline & $\mathrm{C}$ & MSa & MSs \\
\hline MOR (GPa) & $35.0 \pm 1.4 \mathrm{a}$ & $49.8 \pm 6.2 \mathrm{~b}$ & $45.5 \pm 10.1 \mathrm{~b}$ \\
\hline
\end{tabular}

\subsection{Mechanically stimulated trees produce wood with higher resilience and less post-elastic damage}

Wood damage was defined as the loss of wood rigidity after a strain of high intensity. This phenomenon is due to sliding between fibres, irreversible ruptures at the cell scale and micro-cracks during material strain. Our results show that flexure wood and compressive flexure wood were more resistant to this damage process compared to normal wood. Once again, the similarity of their properties suggests that the compressive stress generated during symmetrical stem bending have a prevailing impact on this damage resistance characteristic for $\mathrm{FW}$, as is the case for microfibril angle or basic density changes. Moreover, we observed that damage seems to be well correlated with the microfibril angle (Fig. 9). Thus, cell wall microfibrils of compressive flexure wood and flexure wood seem to adopt a configuration that guarantees a higher deformability for these woods, allowing them to withstand larger displacements with less damage.

Previous studies showed that the elastic modulus (Clair and Thibaut 2014; Evans and Ilic 2001; Xu and Liu 2004; Yang and Evans 2003) is highly correlated with the basic density and microfibril angle (MFA). Considering wood mechanical resilience, in gymnosperms an increase in wood basic density associated with an increase in microfibril angle increase wood toughness, i.e. its capacity to absorb energy before fracture (Burgert 2006; Jungnikl et al. 2009). Our experiment completes these findings for an angiosperm since we observed that compressive flexure wood was denser and presented a higher microfibril angle than normal wood and tensile flexure wood. These structural features explain why compressive flexure wood showed a better resilience to mechanical impact. However, the high variability of our results did not make it possible to draw definitive conclusions about flexure wood, but the results suggest that flexure wood showed a behaviour similar to that of compressive flexure wood, which would be consistent with its high basic density and high microfibril angle.

\subsection{Compressive stresses drive the mechanical behaviour of flexure wood}

Only several studies have investigated the effects of mechanical stimulations on fresh wood mechanical properties. In our study, we applied two types of mechanical stimulations, namely asymmetrical and symmetrical bending treatments, in order to characterise the mechanical properties of flexure wood (symmetrical bending) and also to analyse the separate role of each elementary stress generated during bending, compression and tension, on flexure wood property modulations (asymmetrical bending).

For the first time, our results reveal similarities in the mechanical behaviour of flexure wood and compressive

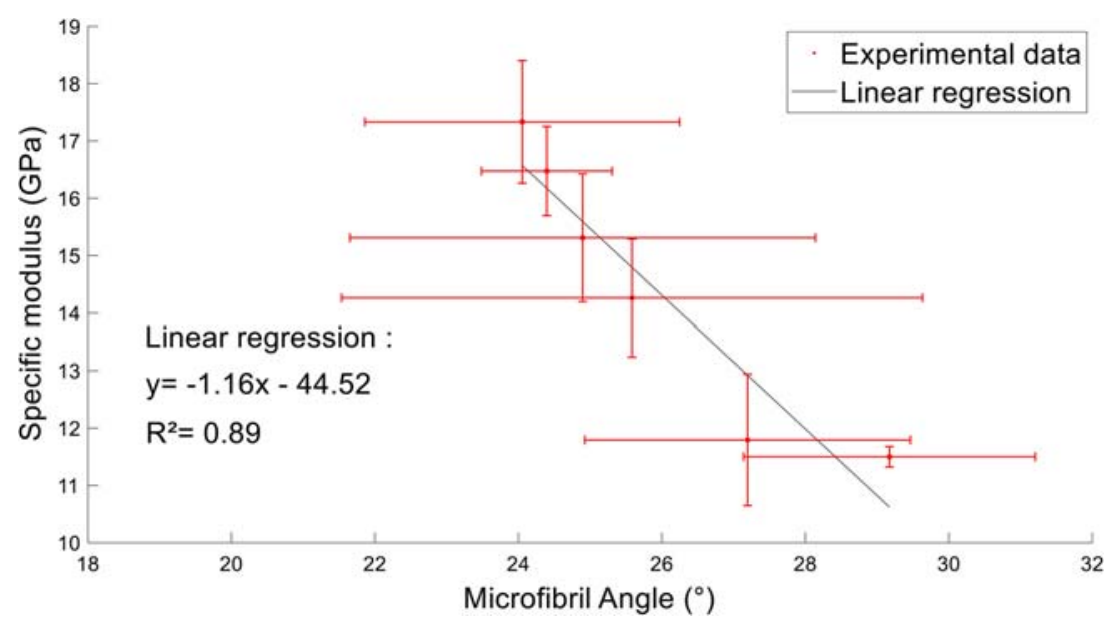

Fig. 8 Relationship between the specific modulus of woods and the microfibril angle of their cell wall. Red points stand for the mean value of the specific modulus and microfibril angle for each type of wood (NW, CFW, TFW, MSa-N, FW and MSs-N). NW represents "normal wood" (no-bending stimulation), TFW (resp. CFW) is wood tissue formed under tensile (resp. compressive) stresses, FW stands for "flexure wood" (tissues alternatively experience compression and tensile strain). MSa-N and MSs-N are wood tissues formed in the neutral area where longitudinal strains are the lowest. The red lines represent the standard deviation 


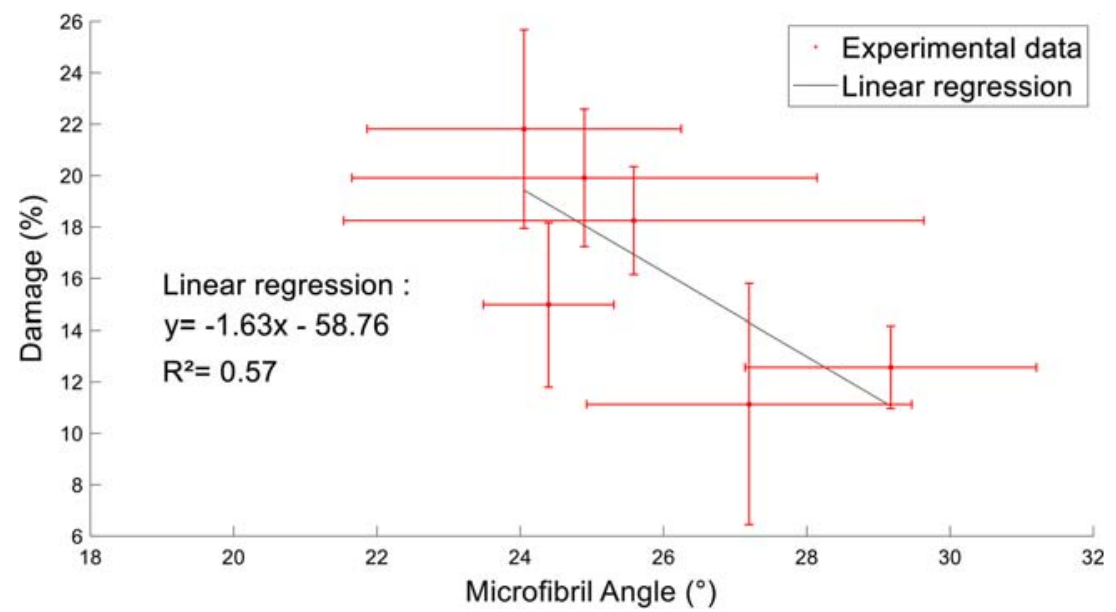

Fig. 9 Relationship between the damage property of woods and the microfibril angle of their cell wall. Relationship between the specific modulus of woods and the microfibril angle of their cell wall. Red points stand for the mean value of the specific modulus and microfibril angle for each type of wood (NW, CFW, TFW, MSa-N, FW and MSs-N). NW represents "normal wood" (no-bending stimulation), TFW (resp.

flexure wood, suggesting that compressive stress generated during stem bending drives the formation of flexure wood and its corresponding mechanical properties. This hypothesis implies that trees would be able to sense the sign of the strain that is applied to the stem, as was previously hypothesised in the work of Roignant et al. (2018) concerning wood anatomy modulations, and in Niez et al. (2018) for the modulations of stem cross-section shape. Moreover, such a control would be very efficient for tree mechanical safety since compressive stress is known to be more critical for wood because of its elongated honeycombed structure consisting of long cells with thin cell walls (Ashby 1983; Bariska and Kucera 1985; Deng et al. 2012; Navi and Heger 2005) and because of the organisation of the helical cellulose in the cell wall.

\subsection{Benefits of flexure wood production for trees submitted to wind}

Few previous studies had looked at the stem mechanical strength (MOR) of trees grown under mechanical stimulations. Telewski and Jaffe (1986a) had shown on loblolly pine that stems of trees acclimated to mechanical stimulations withstood higher-intensity bending than nonstimulated stems. On the other hand, Kern et al. (2005) observed that the MOR of mechanically stimulated poplar hybrids was not different or was even lower than nonstimulated trees (two poplar clones out of seven). Our results are in agreement with Telewski and Jaffe (1986a) since we also observed a resistance gain for the stems of
CFW) is wood tissue formed under tensile (resp. compressive) stresses, FW stands for the "flexure wood" (tissues alternatively experience compression and tensile strain). MSa-N and MSs-N are wood tissues formed in the neutral area where longitudinal strains are the lowest. The red lines represent the standard deviation

mechanically stressed trees. These results on stem rupture strength are consistent with the local modulation of the wood properties (damage and resilience) and suggest that the local modulations of wood properties due to mechanical acclimation provide an improvement of the mechanical behaviour of the stem.

In a previous study, we showed that bending treatments enhance the radial growth of the trees, especially in the direction of the bending (Niez et al. 2018). For poplars, it was shown that such a growth response drastically increases the stem diameter and its bending rigidity and decreases the maximal stresses applied in the risky areas of the cross section of the stem (Niez et al. 2018). In this study, we found that periodic stem bending leads to the formation of a wood with high MFA, which modulates the cell wall mechanical properties and improves the resistance of wood to damage and rupture. As the result of an efficient strategy of biomass distribution (Niez et al. 2018) and the modulation of cell wall properties, the maximal stresses endured by the wood are decreased in the areas of the stem where the mechanical risk is the highest. Taken together, these modulations, at the tree scale and at the tissue scale, improve the ability of the stem to withstand higher bending loading. All these modifications suggest that tree mechanical acclimation to stem bending ensures its mechanical stability and sustainability in fluctuating mechanical environments and provides an adaptive benefit for trees, as can be observed for trees located at the edges of forests (Brüchert and Gardiner 2006; Gardiner et al. 2016). 


\section{Conclusion}

Thigmomorphogenesis has been known for years now to modulate plant growth and their corresponding global mechanical behaviour (Jaffe 1973; Kern et al. 2005; Telewski 1989). Recent studies have shown that mechanical acclimation also generates anatomical modifications at the wood tissue scale (Roignant et al. 2018). Our work has shown that the mechanical behaviour of fresh wood is highly modulated by the thigmomorphogenetic process. Our aim was to demonstrate the resulting separate impacts of compressive and tensile stresses generated during stem bending on the mechanical properties of fresh wood. In order to do this, we designed original methods of sampling (millimetric beams) and of local characterisation of fresh wood mechanical properties (i.e. micro Charpy impact testing machine). Our results show that wood tissues formed under compressive treatments (CFW and FW) have different mechanical behaviours than other tissues ("normal wood" or TFW) mainly due to the modulation of their cell wall microfibril angle. These woods (CFW and FW) have softer cell walls (lower specific modulus) but are more resistant to mechanical strain of high intensity (greater MOR and lower damage property after loading). Roignant et al. (2018) showed that the sign of strain (tensile or compressive) perceived by the tissue is essential for the modulation of the wood structure. In our study, we compared the mechanical properties of wood produced after asymmetrical and symmetrical bending on young poplars to determine which signal is crucial for flexure wood formation. The comparison between flexure wood and compressive flexure wood strongly suggests that compressive strain is the main driver of the changes in wood structure and properties. Such a control would be very efficient for tree mechanical safety since compressive stresses are known to be the most critical stresses for honeycombed materials such as wood. Both flexure wood and compressive flexure wood exhibited higher density and higher microfibril angle compared to normal wood, leading to remarkably higher resistance to damage and higher resilience to fracture. Acclimation of young poplars to bending therefore consists of a modified distribution of biomass allocation around the circumference (Niez et al. 2018), accompanied by a modification of the wood tissue properties in order to provide a better resistance to wind loads, and results in an adaptive benefit process for tree sustainability in fluctuating environments. For the first time, this study explains a part of the acclimation process via the modulation of the mechanical properties at the cellular and tissue levels. We can now ask ourselves if the modulation of the anatomical pattern would also modify the wood hydraulic properties that ensure the second vital function of the tree, sap conduction.

Acknowledgements The authors thank Christelle Boisselet, Patrice Chaleil, Pierre Conchon, Aline Faure, Brigitte Girard, Stéphane Ploquin and Romain Souchal (UMR UCA-INRAE PIAF) for their technical support and the SILVATECH platform for MFA measurements.

Funding information This work was supported by grants from the Auvergne-Rhônes-Alpes Regional Council and EFPA department of National Institute for Agronomic Research (INRAE).

Data availability The data that support the findings of this study are available from the corresponding author upon reasonable request.

\section{Compliance with ethical standards}

Conflict of interest The authors declare that they have no conflict of interest.

Glossary of abbreviations: list and definition. This glossary gathers the growth conditions of the trees (C, MSa, MSs) and the different types of fresh wood $\mathrm{C}$, Control trees; MSa, Trees experiencing asymmetrical mechanical stimulations; MSs, Trees experiencing symmetrical mechanical stimulations; NW, Normal wood: it is formed in the control trees, i.e. without any mechanical stimulations; CFW, Compressive flexure wood: it is formed under repeated compressive strain in MSa trees; TFW, Tensile flexure wood: it is formed under repeated tensile strain in MSa trees; FW, Flexure wood: it is formed alternatively under repeated tensile and compressive strain in MSs trees; MSa-N, Neutral wood formed in the neutral line of MSa trees during the asymmetrical stem bending treatment; MSs-N, Neutral wood formed in the neutral line of MSs trees during the asymmetrical stem bending treatment; NeW, Neutral wood gathering MSa-N and MSs$\mathrm{N}$ : it refers to the wood tissues in the neutral line during the asymmetrical (MSa-N) and symmetrical (MSs-N) stem bending treatment

\section{Appendix}

Table 3 Number of tested samples. C refers to control trees. MSa and MSs refer to stems that experienced asymmetrical and symmetrical bending treatments, respectively. NW represents the "normal wood" (no-bending stimulation), CFW (resp. TFW) refers to wood tissues that experienced compressive (resp. tensile) strain only during the stem bending treatment. MSa-N and MSs-N refer to wood tissues in the neutral line during the asymmetrical (resp. symmetrical) stem bending treatment. FW (flexure wood) refers to wood tissues that alternatively experienced tension and compression strain (symmetrical bending treatment). MOR stands for the modulus of rupture

\begin{tabular}{llccl}
\hline & MOR & $\begin{array}{l}\text { Specific } \\
\text { modulus }\end{array}$ & Damage & Resilience \\
\hline C & 4 & & & \\
MSa & 5 & & & \\
MSs & 2 & & 5 & 3 \\
NW & & 5 & 5 & 4 \\
CFW & & 5 & 4 & 4 \\
TFW & & 4 & 4 & 3 \\
MSa-N & & 4 & 10 & 7 \\
FW & & 10 & 5 & 3 \\
MSs-N & & 5 & & \\
\hline
\end{tabular}


Fig. 10 Experimental dampened sinusoidal signal from the incremental angular position sensor. $\alpha_{\text {initial }}$ stands for the initial position of the pendulum and $\alpha_{\text {final }}$ is the final position of the pendulum after the breakage of the millimetric beam. The difference between these two positions, $\Delta \alpha$, corresponds to the difference of potential energy that matches the total energy dissipated during the test, $\Delta \mathrm{E}$
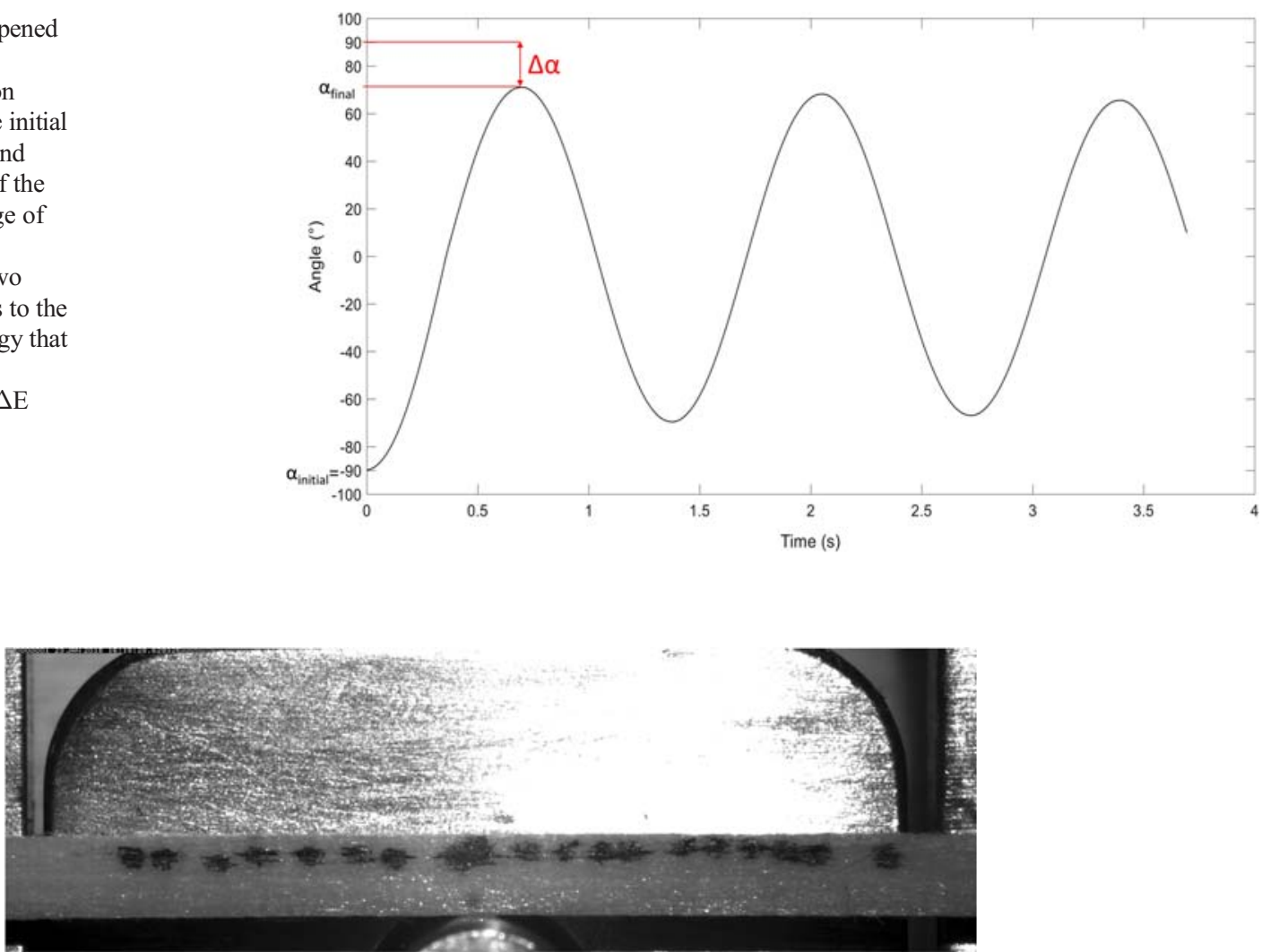

Fig. 11 Micro-bending test monitored by camera (.gif). Black marks have been drawn on the sample in order to monitor the displacement of the sample without contact. The movie depicts the three preliminary loading cycles, the loading cycle to $0.8 \%$ of strain and, finally, the last loading until rupture

\section{References}

Ashby MF (1983) The mechanical properties of cellular solids. Metall Trans A 14:1755-1769. https://doi.org/10.1007/bf02645546

Badel E, Ewers F, Cochard H, Telewski FW (2015) Acclimation of mechanical and hydraulic functions in trees: Impact of the thigmomorphogenetic process. Front Plant Sci 6. https://doi.org/ 10.3389/fpls.2015.00266

Bariska M, Kucera LJ (1985) On the fracture morphology in wood 2. Macroscopical deformations upon ultimate axial-compression in wood. Wood Sci Technol 19:19-34. https://doi.org/10.1007/ bf00354750

Barnett JR, Bonham VA (2004) Cellulose microfibril angle in the cell wall of wood fibres. Biol Rev 79:461-472. https://doi.org/10. 1017/s1464793103006377

Biddington NL (1986) The effects of mechanically induced stress in plants. A review. Plant Growth Regul 4:103-123

Bonnesoeur V, Constant T, Moulia B, Fournier M (2016) Forest trees filter chronic wind-signals to acclimate to high winds. New Phytol. https://doi.org/10.1111/nph.13836

Bornand M, Dejou J, Servant J (1975) Terres noires of Limagne (Massif Central, France)-Various soil facies and their place in french classification. C R Hebd Seances Acad Sci Ser D 281: $1689-1692$

Brüchert F, Gardiner B (2006) The effect of wind exposure on the tree aerial architecture and biomechanics of Sitka spruce (Picea sitchensis, Pinaceae). Am J Bot 93:1512-1521. https://doi.org/10. 3732/ajb.93.10.1512
Burgert I (2006) Exploring the micromechanical design of plant cell walls. Am J Bot 93:1391-1401. https://doi.org/10.3732/ajb.93.10. 1391

Clair B, Thibaut B (2014) Physical and mechanical properties of reaction wood. In: Gardiner B, Barnett J, Saranpaa P, Gril J (eds) Biology of reaction wood. Springer Series in Wood Science. Springer-Verlag, Berlin, pp 171-200. https://doi.org/10.1007/978-3-642-10814-3 6

Coutand C, Moulia B (2000) Biomechanical study of the effect of a controlled bending on tomato stem elongation: local strain sensing and spatial integration of the signal. J Exp Bot 51:1825-1842

Coutand C, Martin L, Leblanc-Fournier N, Decourteix M, Julien JL, Moulia B (2009) Strain mechanosensing quantitatively controls diameter growth and PtaZFP2 gene expression in poplar. Plant Physiol 151:223-232. https://doi.org/10.1104/pp.109.138164

Deng Q, Li S, Chen YP (2012) Mechanical properties and failure mechanism of wood cell wall layers. Comput Mater Sci 62:221-226. https://doi.org/10.1016/j.commatsci.2012.05.050

Evans R, Ilic J (2001) Rapid prediction of wood stiffness from microfibril, angle and density. For Prod J 51:53-57

Fournier M, Stokes A, Coutand C, Fourcaud T, Moulia B (2006) Tree biomechanics and growth strategies in the context of forest functional ecology. In: STaRNe HA (ed) Ecology and biomechanics : a biomechanical approach of the ecology of animals and plants. CRC Taylor and Francis, Boca Raton, pp 1-33

Gardiner B, Berry P, Moulia B (2016) Review: Wind impacts on plant growth, mechanics and damage. Plant Sci 245:94-118. https://doi. org/10.1016/j.plantsci.2016.01.006 
Haarsma RJ et al (2013) More hurricanes to hit western Europe due to global warming. Geophys Res Lett 40:1783-1788. https://doi.org/ $10.1002 /$ grl. 50360

Hawcroft M, Walsh E, Hodges K, Zappa G (2018) Significantly increased extreme precipitation expected in Europe and North America from extratropical cyclones. Environ Res Lett 13:124006

Jaffe MJ (1973) Thigmomorphogenesis. The response of plant growth and development to mechanical stimulation. Planta 114:143-157

Jaffe MJ, Telewski FW, Cooke PW (1984) Thigmomorphogenesis. On the mechanical properties of mechanically perturbed bean plants. Physiol Plant 62:73-78

Jourez B (1997) Tension wood. 1. Definition and distribution in the tree. Biotechnol Agron Soc Environ 1:100-112

Jourez B, Avella-Shaw T (2003) Effect of gravitational stimulus duration on tension wood formation in young stems of poplar ( $\mathrm{P}$ euramericana ev 'Ghoy'). Ann For Sci 60:31-41. https://doi.org/ 10.1051/forest:2002071

Jungnikl K, Goebbels J, Burgert I, Fratzl P (2009) The role of material properties for the mechanical adaptation at branch junctions. Trees Struct Funct 23:605-610. https://doi.org/10.1007/s00468-0080305-9

Kern KA, Ewers FW, Telewski FW, Koehler L (2005) Mechanical perturbation affects conductivity, mechanical properties and aboveground biomass of hybrid poplars. Tree Physiol 25:1243-1251

Mader M et al (2016) Whole-genome draft assembly of Populus tremula x P-alba clone INRA 717-1B4. Silvae Genet 65:74-79. https://doi. org/10.1515/sg-2016-0019

Moulia B, Coutand C, Julien J-L (2015) Mechanosensitive control of plant growth: bearing the load, sensing, transducing and responding. Front Plant Sci 6:20 p. https://doi.org/10.3389/fpls.2015.00052

Murashige T, Skoog F (1962) A revised medium for rapid growth and bio assays with tobacco tissue cultures. Physiol Plant 15:473-497. https://doi.org/10.1111/j.1399-3054.1962.tb08052.x

Navi P, Heger F (2005) Approche micromécanique du comportement mécanique du bois. In: Comportement thermo-hydromécanique du bois: applications technologiques et dans les structures. PPUR Presses Polytechniques, Lausanne, pp 167-215

Neel PL, Harris RW (1971) Motion-induced inhibition of elongation and induction of dormancy in Liquidambar. Science 173:58. https://doi. org/10.1126/science.173.3991.58

Niez B, Dlouha J, Moulia B, Badel E (2018) Water-stressed or not, the mechanical acclimation is a priority requirement for trees. TreesStruct Funct. https://doi.org/10.1007/s00468-018-1776-y

Perbal G, Drissecole D (1993) Microgravity and root gravitropism. Acta Bot Gallica 140:615-632. https://doi.org/10.1080/12538078.1993. 10515642

Pruyn ML, Ewers BJ, Telewski FW (2000) Thigmomorphogenesis: changes in the morphology and mechanical properties of two
Populus hybrids in response to mechanical perturbation. Tree Physiol 20:535-540

Roignant J, Badel E, Leblanc-Fournier N, Brunel-Michac N, Ruelle J, Moulia B, Decourteix M (2018) Feeling stretched or compressed? The multiple mechanosensitive responses of wood formation to bending. Ann Bot:1-11. https://doi.org/10.1093/aob/mcx211

Ruelle J (2014) Morphology, anatomy and ultrastructure of reaction wood. In: BGJBPS JG (ed) The biology of reaction wood. Springer-Verlag, Berlin Heidelberg, pp 13-35

Telewski FW (1989) Structure and function of flexure wood in Abies fraseri. Tree Physiol 5:113-121

Telewski FW (1995) Wind-induced physiological and developmental responses in trees. In: Coutts MP, Grace J (eds) Wind and Trees. Cambridge University Press, Cambridge, pp 237-263

Telewski FW (2016) Flexure wood: mechanical stress induced secondary xylem formation. In: Secondary xylem biology: origins, functions, and applications. Academic, Cambridge, pp 73-91

Telewski FW, Jaffe MJ (1986a) Thigmomorphogenesis - anatomical, morphological and mechanical analysis of genetically different sibs of Pinus taeda in response to mechanical perturbation. Physiol Plant 66:219-226. https://doi.org/10.1111/j.1399-3054.1986.tb02412.x

Telewski FW, Jaffe MJ (1986b) Thigmomorphogenesis - field and laboratory studies of Abies fraseri in response to wind or mechanical perturbation. Physiol Plant 66:211-218. https://doi.org/10.1111/j. 1399-3054.1986.tb02411.x

Telewski FW, Pruyn ML (1998) Thigmomorphogenesis: a dose response to flexing in Ulmus americana seedlings. Tree Physiol 18:65-68

Timoshenko SP (1930a) Strength of materials, vol 1. D. Van Nostrand Company, Inc, Princeton

Timoshenko SP (1930b) Strength of materials, vol 2. D. Van Nostrand Company, Inc, Princeton

Verrill SP, Kretschmann DE, Herian VL (2006) JMFA2 - a graphically interactive Java program that fits microfibril angle X-ray diffraction data. Research Paper FPL-RP-635, vol 69. US Department of Agriculture, Forest Service, Forest Products Laboratory, Madison, p 635

Xu P, Liu H (2004) Models of microfibril elastic modulus parallel to the cell axis. Wood Sci Technol 38:363-374. https://doi.org/10.1007/ s00226-004-0235-7

Yang JL, Evans R (2003) Prediction of MOE of eucalypt wood from microfibril angle and density. Holz Roh Werkst 61:449-452. https://doi.org/10.1007/s00107-003-0424-3

Publisher's note Springer Nature remains neutral with regard to jurisdictional claims in published maps and institutional affiliations. 